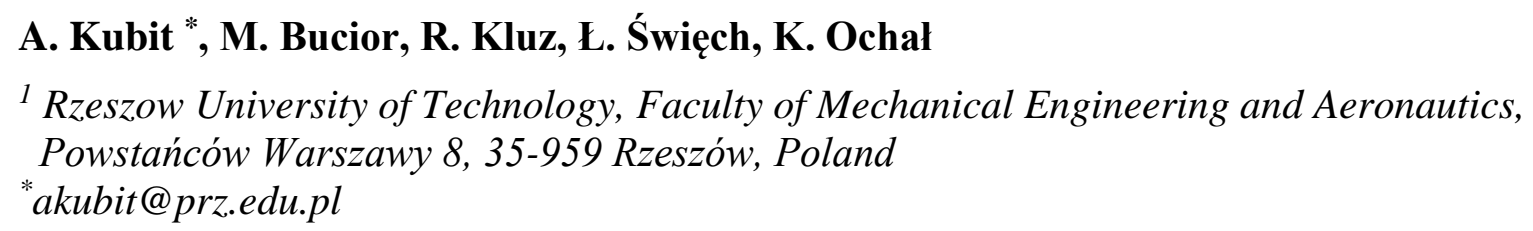

\title{
APPLICATION OF THE 3D DIGITAL IMAGE CORRELATION TO THE ANALYSIS OF DEFORMATION OF JOINTS WELDED WITH THE FSW METHOD AFTER SHOT PEENING
}

\begin{abstract}
The three dimensional Digital Image Correlation (3D DIC) method is used for measurements of deformations and displacement in plane elements exposed to loading. The paper presents the experimental tests of an application of the ARAMIS system to the analysis of deformation of joints welded with the FSW method after shot peening treatment. The butt joints were made of 2024-T3 aluminum alloy sheets with the thickness of 1 $\mathrm{mm}$, which next were peened with glass beads about granulation in range $500 \div 900 \mu \mathrm{m}$. Tests of residual stresses by X-ray diffraction were also carried out. The aim of the study was to analyze the impact of shot peening on the value of stresses and the location of deformations in butt joints.
\end{abstract}

Keywords: FSW method, shot peening, 2024-T3 aluminum alloy

\section{INTRODUCTION}

Friction stir welding (FSW) technology is one of the most promising solid state process which can be used to reduce structure weights and costs in aerospace industry [1,2]. This method can be an alternative to other joining technologies, such as riveting, adhesive bonding or welding. During FSW method, the material does not melting and the joints is free of typical defects arising in the solidification process, such as precipitation, segregation or gas porosity as is the case with remelting processes. This method can be used to join the materials which are difficult to join using conventional welding [3] such as aluminum alloys [4] copper [5], magnesium alloy [6,7], steels [8] or even dissimilar materials $[9,10]$. The resulting weld has an equiaxial shape and its grains reach a size of 1-10 $\mu \mathrm{m}$. During the FSW process, unfavorable tensile stresses are introduced, which in effect weaknesses the connection. Tensile stresses can be reduced by another technologies such as static burnishing [11], laser 
peening or shot peening [1]. Shot peening is one of the burnishing methods, which is used as strengthening treatment. In this method the various media such as ceramic or glass balls striking at a high speed on the workpiece, which cause plastic deformation and generate compressive stress. In turn this stresses increase the fatigue strength of material.

An important issue related to FSW welded joints is also the measurement of deformations. The three-dimensional Digital Image Correlation (3D DIC) technique can be used to detection of local deformations and displacements in areas of geometric discontinuity and heterogeneity of material, among others allows for the detection of cracks on the surfaces of objects studied. This method also allows for measuring surface deformation and analyzing

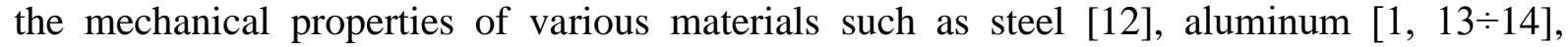
titanium [15] and composites [16]. Obvious advantages of this method are non-contact measurements, high sensitivity measurements can determine the displacements and strains in any area of the measurement zone, the measurement range starting from nanoscale and give the possibility of measurements on the real constructions in exploitation time [17]. Lusiak and Knec [16] presented this measurement method for fatigue process control in the accelerated test for composites. They concluded that the main advantage of ARAMIS system is a very limited amount of specimens required for fatigue test.

The use of DIC technique for accessing local strain fields and the stress distribution in FSW welded joins, has been previously studied by other authors. Wang et al. [14] studied the hot deformation behavior of 2024-T4 aluminum alloy after welding FSW method. They used DIC system to probe the full strain fields during the free bulging test. In turn, authors of work [12] analyzed the joining of thin steel plates by the FSW method, and then assessed weld strength and plastic properties using the DIC system. Leităo et al. [18] presented the procedure for characterizing the constitutive behaviour of welds with using the DIC system. This methodology is based on a comparison of local stress-strain curves obtained by testing transverse weld samples of friction stir welds in very thin plates with those obtained by testing longitudinal samples of the same welds.

The DIC technique was also used in another areas. Hatamleh et al. [1] presented the effect from laser and shot peening (SP) on the mechanical properties of FSW 2195-T8 aluminum alloy investigated at elevated and cryogenic temperatures. They used a DIC system for evaluated the local strains and equivalent tensile properties at different regions of the weld. The residual stresses was measured by using X-ray diffraction and the contour method. They pointed out a decrease in surface grain size after laser peening when compared to the welded specimens. Moreover after laser peened specimens indicated an increase of 32\% to the $0.2 \%$ offset yield strength of the material in the weld nugget region when tested at the high temperature $\left(182^{\circ} \mathrm{C}\right)$. In comparison, shot peening exhibited only modest improvement on the yield strength which was $8 \%$. The specimens tested at cryogenic temperature $\left(-100{ }^{\circ} \mathrm{C}\right)$ also resulted in an increase to the tensile properties but the difference between peened and unpeened specimens was small. In turn Xu and Bao [2] examined the residual stress in 2024T351 AA friction stir butt welds thin plate using the traditional residual stress measurement methods and the advanced optical technique. They concluded that residual stresses obtained by the DIC technique is consistent with the evaluations given by X-ray diffraction.

In the present study, the application of the 3D DIC to the analysis of deformation of joints welded with the FSW method after shot peening was presented. Joints were made using the FSW method and next were peened at various technological parameters. The residual stresses and strain distribution were analyzed after SP. 


\section{MATERIAL AND METHODS}

This paper presents the results of research regarding the location of butt joints deformations using the ARAMIS system. The joints made of the FSW method in the next stage of research were subjected to glass beads at various technological parameters of the process and the residual stress was measured by X-ray diffraction. Aluminum alloy 2024 in T3 state with a $1 \mathrm{~mm}$ thickness was used in this investigation. This type of alloy is mainly used for many aerospace applications. Aluminum alloys of the $2 \mathrm{xxx}$ series due to their high copper content have high mechanical properties and a higher yield strength. The FSW process was conducted on a universal vertical milling machine. The welding process was performed with a tool rotational speed of $1300 \mathrm{rpm}(\mathrm{n})$ and a feed rate of $50 \mathrm{~mm} / \mathrm{min}$ (f). The inclination angle of the tool was $3^{\circ}$. Two sheets of aluminum alloy, were butt-welded in a perpendicular direction to the line of the weld formed. Then, $30 \mathrm{~mm}$ wide specimens were cut from the welded sheets. These specimens, next were used in shot peening treatment. Pneumatic shot peening process was performed on a special device, according to variants presented in Table 1. A diameter of the glass beads, was in the $d_{b}=500 \div 900 \mu \mathrm{m}$ range. The distance of the specimen to the nozzle was $1=250 \mathrm{~mm}$.

Table 1. Shot peening parameters adopted in tests

\begin{tabular}{ccc}
\hline & \multicolumn{2}{c}{ Parameter } \\
\cline { 2 - 3 } & $\mathrm{t}, \mathrm{min}$ & $\mathrm{p}, \mathrm{MPa}$ \\
\hline Base variant & - & - \\
\hline $\mathrm{SP} 1$ & 1 & 0.4 \\
\hline $\mathrm{SP} 2$ & 3 & 0.4 \\
\hline $\mathrm{SP} 3$ & 1 & 0.5 \\
\hline *t - time, $\mathrm{p}-$ pressure & & \\
\hline
\end{tabular}

Residual stress measurements were made using a X-ray diffractometer Proto iXRD Combo and computer software XRD Win 2.0 by Proto Manufacturing. The measurements were carried out at the Department of Materials Science at Rzeszow University of Technology. The residual stress were measured at two points on the specimen in a transverse and longitudinal direction on a weld center before and after shot peening. In order to calculate the values of residual stresses at a given measuring point, the $\sin 2 \Psi$ [19] method was used. This method is based on the use of Bragg-Brentan symmetrical diffraction. The device is equipped with a $\Psi$ type goniometer, which allows obtaining appropriate inclinations of the diffraction vector by angles $\Psi_{\mathrm{i}}$ in the plane perpendicular to the diffraction plane [20]. The stresses were determined for the constant values of the angle $\Psi$ in the range from $25^{\circ}$ to -25 $\circ$ The X-ray diffractometer used the monochrome radiation of the chromium anode lamp $(\lambda=$ $2.291 \AA$, $4 \mathrm{~mA}$ anode current and $20 \mathrm{kV}$ anode voltage).

The stand for testing by the 3D DIC method and the manner of specimen attachment is shown in Fig. 1. Taking into account the results of previous studies [21, 22], which showed that the samples after FSW welding were destroyed in the weld area and heat affected zone, the specimens for the tensile test were made with dimensions of $30 \times 160 \mathrm{~mm}$. The tensile test 
were subjected in accordance with norm ISO 6892-1. The ARAMIS measuring system consists of two components. The first is the scanner, consisting of two high resolution digital cameras, which are located in a way that allows you to build a spatial image. The second element of the setup is a computer with special software for numerical processing of photos that are created during research. The system takes photos at a maximum speed of 25 frames per second. The specimen should be properly prepared before testing. In the first step, it is covered with white, matte paint, which should be next sprayed with black paint. The sample prepared in this way is attached in the holder (Fig. 1b). The measurement consists of taking a series of photos in subsequent loading phases. The components of the displacement state are determined during loading. Then, the specified displacement values are used to calculate the components of the deformation state in the form of a field image.

a)

b)

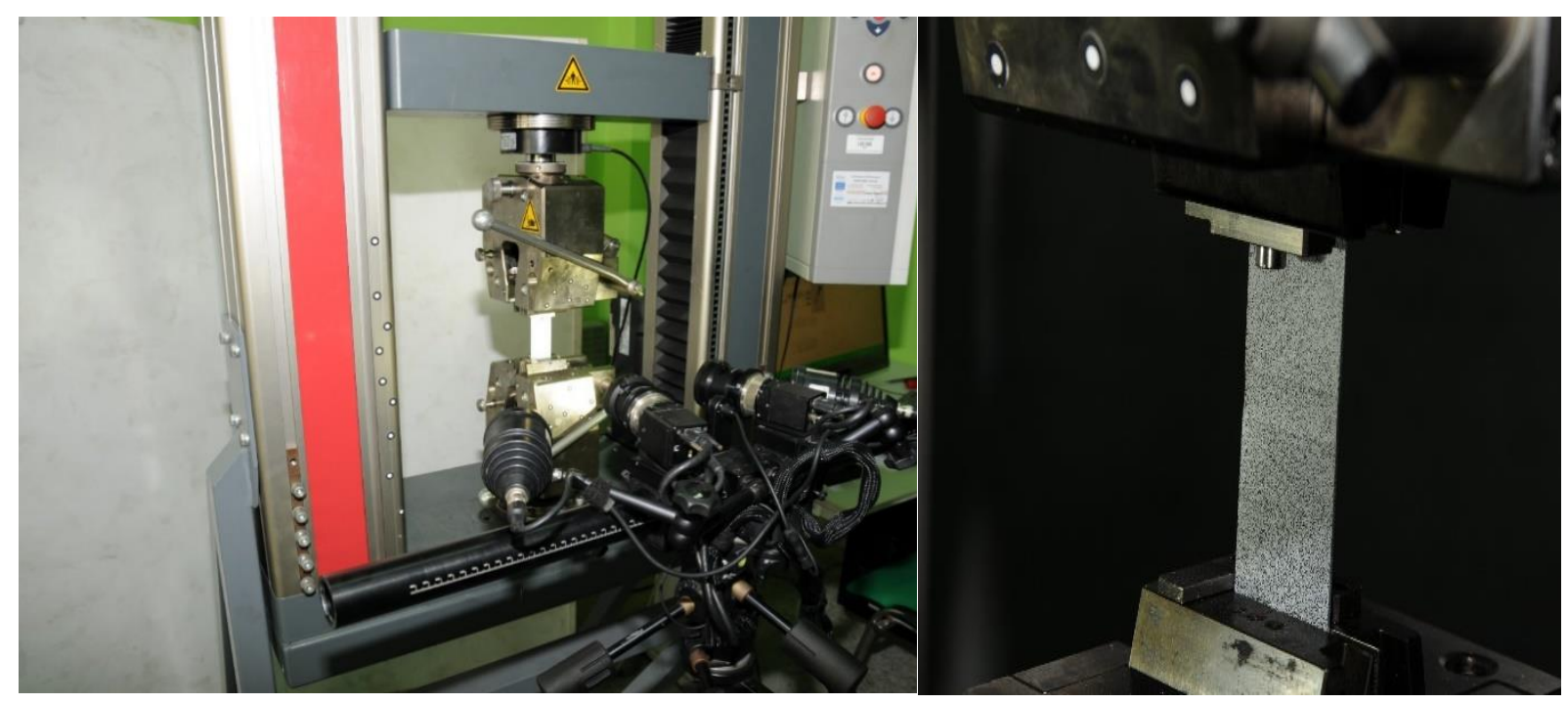

Fig. 1. Experimental setup (a) and method of specimen attachment (b)

\section{RESULTS}

\section{$\underline{\text { Residual stress }}$}

Measurement points on the residual stresses in a transverse $\left(\sigma_{\mathrm{x}}\right)$ and longitudinal $\left(\sigma_{\mathrm{y}}\right)$ direction for analyzed variants are shown in Figs. 2 and 3, respectively (4 points on the transverse direction and 4 points on the longitudinal direction). The final effect of the measurement is the stress value and the error. If we analyze the way the device performs the measurement, each of these points consists of several measurements (in this case was 7 measurements), which were made at the appropriate angle from $25^{\circ}$ to $-25^{\circ}$. Then the algorithm of the XRD Win 2.0 program analyzes the measurements and we get the average final result with an error. Analyzing the presented results, it can be noticed that the unfavorable tensile residual stresses was obtained for the specimens after welding in a longitudinal direction $\sigma_{\mathrm{y}}=4.46 \mathrm{MPa}$. In turn, shot peening process introduces the compressive residual stresses at value $\sigma_{\mathrm{x}}=-172.83 \mathrm{MPa}$ on the surface layer. In the case of SP specimens, it can be seen that the measuring direction does not significantly affecting to the stress value. The measured stress values are within the error limits. However, a significant 
difference can be observed for the specimen after welding (base variant), where the difference between the measurement in the longitudinal and transverse directions was 66.7 MPa. The highest values of compressive stresses were obtained for specimens peened according to variants SP1 and SP2. On this basis, it can be concluded that in this case the peened time, which was $1 \mathrm{~min}$ and $3 \mathrm{~min}$ for variants SP1 and SP2, respectively, did not significantly affecting to the values of stresses obtained. Compared the stresses measured for specimens peened according to the SP3 variant, it can be noticed that the increase in pressure unfavorable affecting to the distribution of stresses. Shot peening treatment causes a compressive residual stresses increased from 59 to $64 \%$ in the transverse direction, and from 95 to $97 \%$ in the longitudinal direction compared to the stress of FSW treatment. Summarizing, it can be concluded that the shot peening of a $1 \mathrm{~mm}$ thick 2024-T3 aluminum alloy sheet with parameters according to the SP1 and SP2 variants are the most effective and economical.

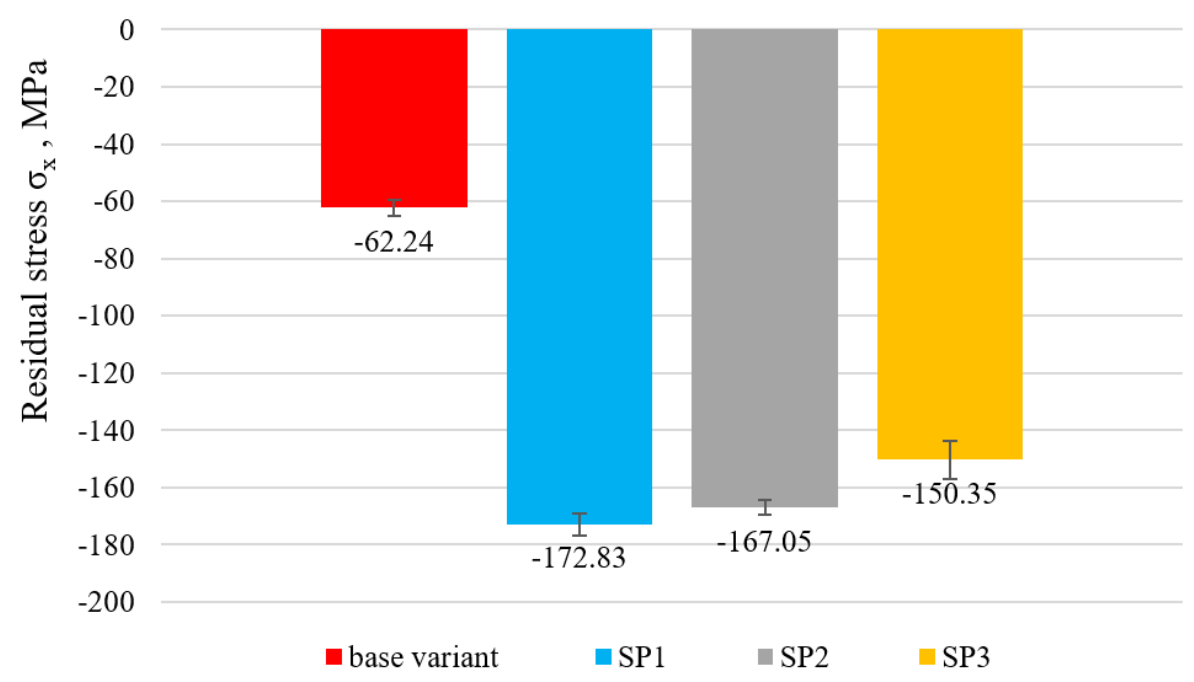

Fig. 2. Residual stress in a transverse direction

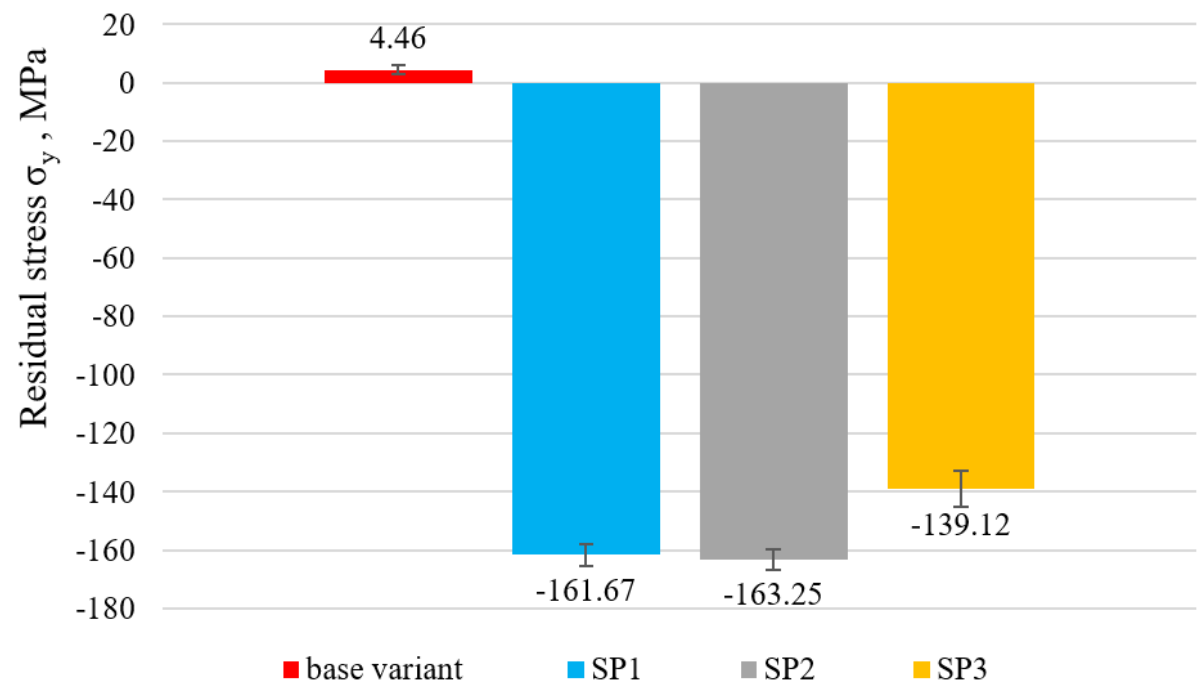

Fig. 3. Residual stress in a longitudinal direction 


\section{Strain distribution}

The strain distribution maps at maximum load level and specimens after failure in Table 2 clearly show that the failure of the SP1 variant occurred in the weld area after significant plastic deformation took place.

Table 2. Strain distributions maps right before failure (a) and (b) specimens after failure

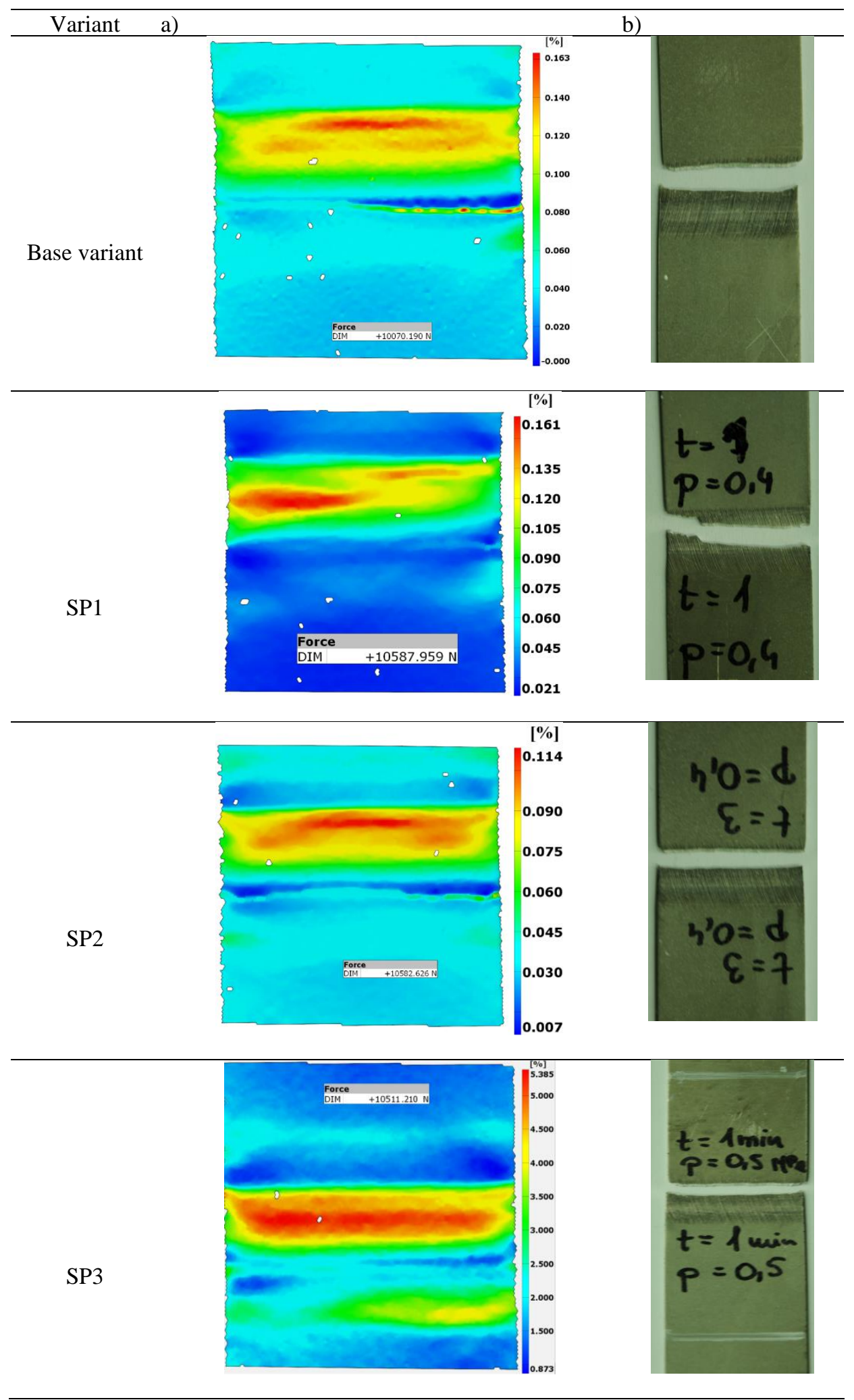


For the others variants, the crack occurred at the edge of the weld. In the case of the base variant and SP3, the maps show deformations occurring in two places, at the weld edge and in the weld area. Unfavorable deformation distribution can also be observed for the SP1 variant. Such deformation distributions reduce the strength properties of the weld. Incorrect selection of shot peening parameters, as in the case of the SP1 variant, where there is an asymmetrical distribution of deformations, can also cause a crack in the weld area. The peening sample for $t$ $=3$ min under pressure $\mathrm{p}=0.4 \mathrm{MPa}(\mathrm{SP} 2)$ give the best results. In this case, the deformation distribution before cracking is even and does not weaken the weld.

The tests showed that there is a strong correlation between stresses and the force $(\mathrm{F})$ at which the samples were destroyed. The correlation coefficient was 0.99. After shot peening according to the SP1 variant (where the value of compressive stress was $\sigma_{\mathrm{x}}=-172.83 \mathrm{MPa}$ ) the force at which the destruction occurs increased by $\mathrm{F}=517.8 \mathrm{~N}$ compared to the Base variant. In turn, for the SP3 variant where the lowest compressive stress value equal to $\sigma_{\mathrm{y}}=-$ 139.12 MPa was obtained, the force increased by $\mathrm{F}=440.8 \mathrm{~N}$.

A view of deformations according to load level for SP3 variant is shown in Fig. 4. The increase in load is accompanied by an increase in deformation. Analyzing the presented deformations for the selected four load levels, it can be seen that the deformation begins near the weld edge at a load of about $7000 \mathrm{~N}$ (Fig. 4b). The deformation propagation runs in the longitudinal direction.

a)

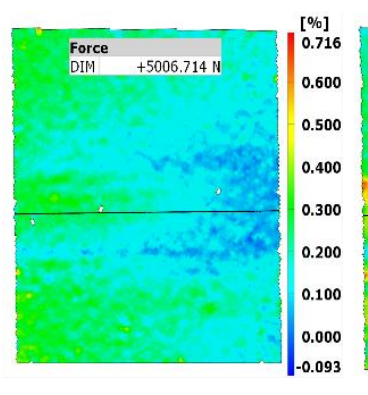

b)

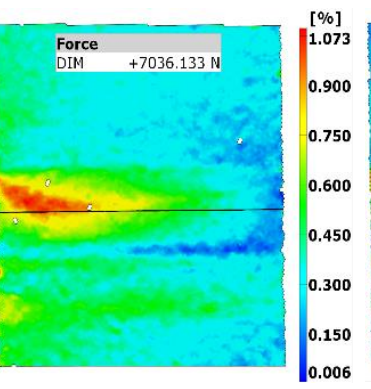

c)

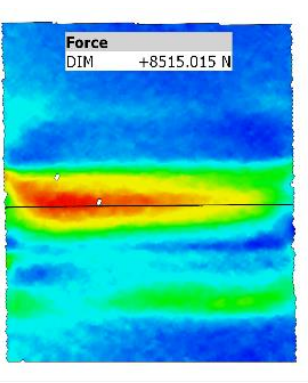

d)

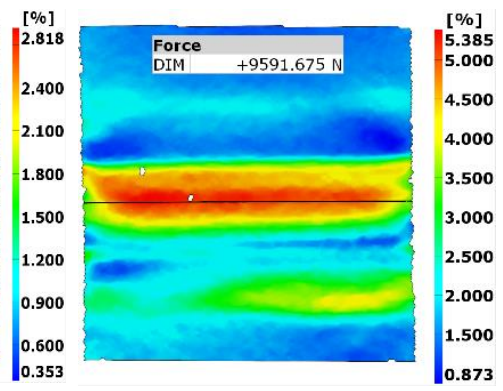

Fig. 4. View of deformation according to load level for SP3 variant

The force - elongation curves determined for analyzed specimens are shown in Fig. 5. Analyzing the obtained results it is possible to conclude that specimens after SP displayed very similar mechanical properties values compared to the specimens after welding FSW method. The values of the yield stress $R_{e}$ as well as the tensile stress $R_{m}$ the specimens after SP did not change significantly compared to the base variant. On the other hand, a significant difference can be observed by analyzing the distribution of deformation along the length of the specimen cross - section at the place of maximum principal strain (Fig. 6). In the case of the SP1 variant, an uneven distribution of deformation can be seen, which in turn causes weakening of the welded joint and cracking through the center of the weld. 


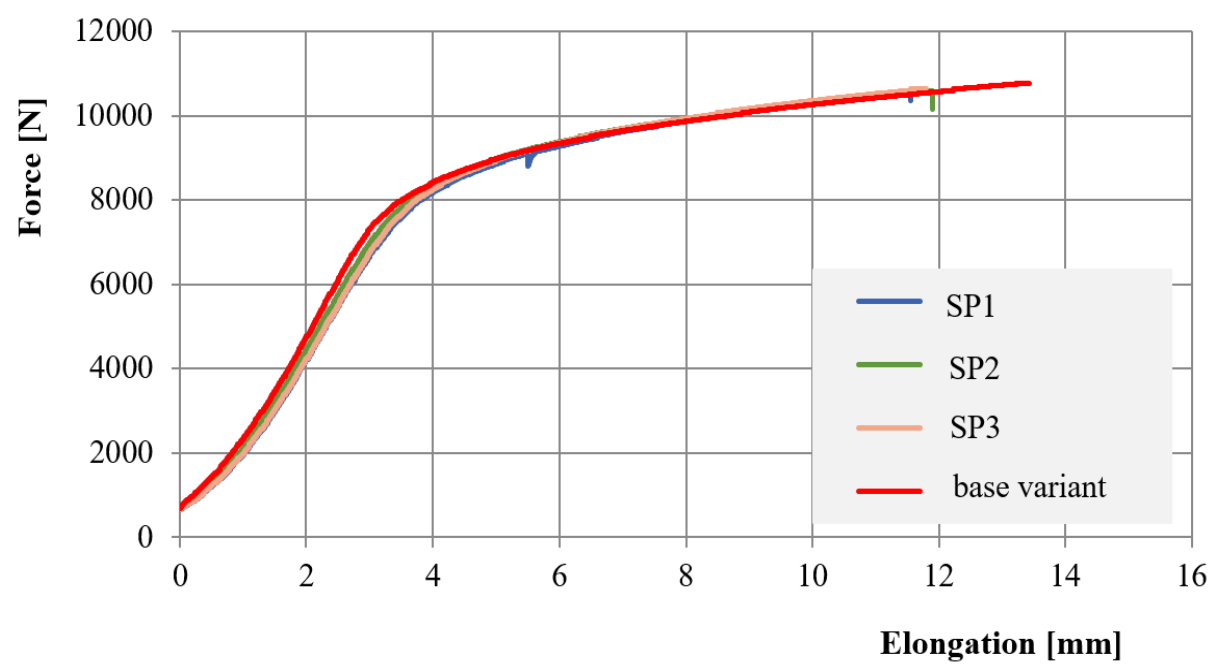

Fig. 5. The force - elongation diagram

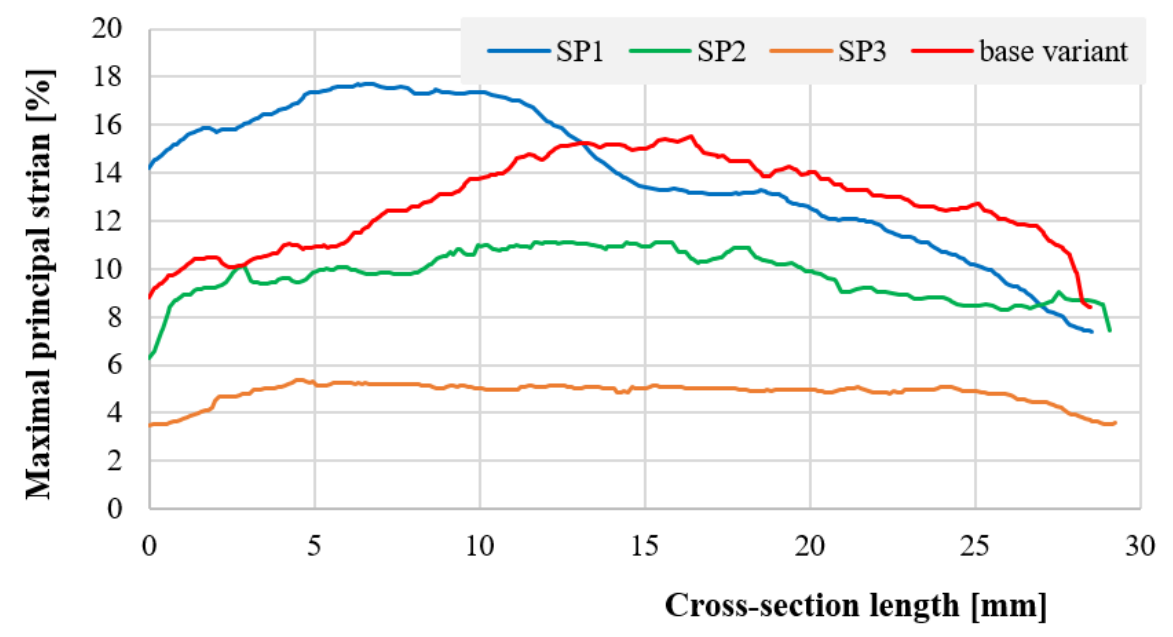

Fig. 6. Distribution of deformation along the length of the cross-section (left to right) at the maximum principal strain

\section{CONCLUSIONS}

In the present work, the strain distribution and residual stress of FSW 2024-T3 aluminum alloy sheet before and after shot peening was analyzed. Following conclusions are drawn:

1. Shot peening of welded specimens by FSW method introduces compressive residual stresses reaching the values in range of $\sigma_{\mathrm{x}}=-150.35 \mathrm{MPa}$ to $-172.83 \mathrm{MPa}$ in a transverse direction and from $\sigma_{\mathrm{y}}=-139.12 \mathrm{MPa}$ to $-161.67 \mathrm{MPa}$ in a longitudinal direction.

2. The most regular strain distributions of FSW sheet were in variant SP2, the deformations were concentrated at the edge of the weld. 
3. Inappropriate selection of SP parameters can weaken the butt welded joints. It can be observed for the SP1 variant. Asymmetrical strain distribution causes a crack in the weld area. This may be due to the short peening time, which was in this case $1 \mathrm{~min}$.

4. Based on the test results, it was found that there is a strong correlation between stresses in the FSW welded joint and the force at which the sample is destroyed. The correlation coefficient was 0.99. This gives the possibility of determining of stress values in the joint without the need for time-consuming measurements of stress.

5. For the peening time of $3 \mathrm{~min}$ and a pressure $0.4 \mathrm{MPa}(\mathrm{SP} 2)$ at the next stage of the study, fatigue strength tests should have been carried out.

\section{REFERENCES}

1. Hatamleh O., Mishra R. S., Oliveras O.: Peening effects on mechanical properties in friction stir welded AA 2195 at elevated and cryogenic temperatures. Materials and Design, 30 (2009) 31653173.

2. Xu Y., Bao R.: Residual stress determination in friction stir butt welded joints using a digital image correlation-aided slitting technique. Chinese Journal of Aeronautics, 30 (2017) 1258-1269.

3. Padhy, G. K., Wu, C. S., Gao, S.: Friction stir based welding and processing technologiesprocesses, parameters, microstructures and applications: A review. Journal of Materials Science \& Technology, 34 (2018) 1-38.

4. Tashkandi M. A., Al-Jarrah J. A.: Ibrahim M. Increasing of the mechanical properties of friction stir welded joints of 6061 aluminum alloy by introducing alumina particles. Advances in Materials Science, 17 (2017) 29-40.

5. Guan W., Shen Y., Yan Y., Guo R., Zhang W.: Fabrication of ultra-thin copper foil pressure welding using FSW equipment. Journal of Materials Processing Tech., 251 (2018) 343-349.

6. Tuz L., Kołodziejczak P., Kolasa A.: Friction stir welding of AZ91 and AM-Lite magnesium alloys. Welding International, 27 (4) (2011) 265-267.

7. Iwaszko, J., Kudła, K., Fila, K., Strzelecka, M.: The Effect of Friction Stir Processing (FSP) on the Microstructure and Properties of AM60 Magnesium Alloy. Archives of Metallurgy and Materials, 61(3) (2016) 1555-1560.

8. Emami S., Saeid T., Abdollah-zadeh A.: Effect of friction stir welding parameters on the microstructure and microtexture evolution of SAF 2205 stainless steel. Journal of Alloys and Compounds, 810 (2019) 1-7.

9. Kasai H., Morisada Y., H. Fujii.: Dissimilar FSW of immiscible materials: Steel/magnesium. Materials Science \& Engineering A, 624 (2015) 250-255.

10. Gao Y., Morisada Y., Fujii H., Liao J.: Dissimilar friction stir lap welding of magnesium to aluminum using plasma electrolytic oxidation interlayer. Material Science and Engineering A, 711(10) (2018) 109-118.

11. Sánchez Egea A.J., Rodríguez A., Celentano D., Calleja A., López de Lacalle L.N.: Joining metrics enhancement when combining FSW and ball-burnishing in a 2050 aluminium alloy. Surface \& Coatings Technology, 367 (2019) 327-335.

12. Mira-Aguiar T., Verdera D., Leitao C., Rodrigues D. M.: Tool assisted friction welding: A FSW related technique for the linear lap welding of very thin steel plates. Journal of Materials Processing Technology, 238 (2016) 73-80. 
13. Xu W., Luo Y., Zhang W., Fu M.: Comparative study on local and global mechanical properties of bobbin tool and conventional friction stir welded 7085-T7452 aluminum thick plate. Journal of Materials Science \& Technology, 34 (2018) 173-184.

14. Wang Z. B., He Z. B., Fan X. B., Zhou L., Lin Y. L., Yuan S. J.: High temperature deformation behavior of friction stir welded 2024-T4 aluminum alloy sheets. Journal of Materials Processing Tech., 247 (2017) 184-191.

15. Saranath K. M., Ramji M.: Local zone wise elastic and plastic properties of electron beam welded Ti-6Al-4V alloy using digital image correlation technique: A comparative study between uniform stress and virtual fields method. Optics and Lasers in Engineering, 68 (2015) 222-234.

16. Lusiak T., Knec M.: Use of ARAMIS for fatigue process control in the accelerated test for composites. Transportation Research Procedia, 35 (2018) 250-258.

17. Zielecki W., Kubit A., Święch Ł.: Experimental analysis of strain field of adherent in adhesive joint subjected to peel. Measurements Automation Robotics, 2 (2013) 71-78.

18 . Leităo C., Galvăo I., Leal R.M., Rodrigues D.M.: Determination of local constitutive properties of aluminium friction stir welds using digital image correlation. Materials and Design, 33 (2012) 69-74.

19. Bonarski J. T.: Pomiar i wykorzystanie teksturowo - naprężeniowej charakterystyki mikrostruktury w diagnostyce materiałów. Instytut Metalurgii i Inżynierii Materiałowej. Kraków. (2013).

20. Skrzypek S. J.: Nowe możliwości pomiaru makronaprężeń własnych materiałów przy zastosowaniu dyfrakcji promieniowania $\mathrm{X} w$ geometrii stałego kąta padania. Wydawnictwo AGH. Kraków. (2002).

21. Kluz R., Kubit A.: Effect of friction stir welding on the load capacity of the joint 2016, Assembly Techniques and Technologies, 2 (2016) 31-34.

22. Kubit A., Kluz R., Ochałek K., Wydrzyński D., Trzepieciński T.: Friction stir welding of 2024T3 Aluminium alloy sheet with sheet pre-heating. Materials and Technology, 52(3) (2018) 283288. 